\title{
Assessment of left ventricular function in coronary artery disease with the nuclear probe during intervention studies
}

\author{
AVIJIT LAHIRI, MICHAEL J BOWLES, RODERICK I JONES, „ JOHN C W CRAWLEY, \\ EDWARD B RAFTERY \\ From the Department of Cardiology and the Divisions of Clinical Sciences and Radioisotopes, Northwick Park \\ Hospital and Clinical Research Centre, Harrow, Middlesex
}

SUMMARY The nuclear probe was used for measuring left ventricular function in 11 normal subjects and the results compared with those using a digital gammacamera. The probe was then used to measure left ventricular function in patients with coronary artery disease during dynamic exercise and stress atrial pacing. The ability of the probe to detect changes induced by glyceryl trinitrate was also evaluated in separate parallel studies. In the 11 normal subjects there was a good correlation between the left ventricular ejection fraction measured by the gammacamera and the nuclear probe both at rest and during exercise. Exercise increased this value by at least $5 \%$ in all normal subjects during measurements with both the gammacamera and the nuclear probe. The mean (SD) difference was $-0.3 \%(2.60)$ at rest and $2.3 \%(5.02)$ at peak exercise. Both exercise and pacing produced angina in the patient group and the mean (SEM) value fell from $52 \%(3.5)$ to $28 \%(2.6)$ and from $46 \%(5 \cdot 1)$ to $34 \%(3.2)$ respectively. Glyceryl trinitrate prolonged the exercise and pacing times, and the corresponding falls in ejection fraction were significantly reduced.

The non-imaging nuclear probe is a cheap and portable instrument capable of assessing left ventricular function in patients with cardiac disease. It is designed for high count rate acquisition over a short period of time and can thus provide both beat to beat and summated left ventricular time activity curves suitable for quantitative analysis. It therefore has important advantages in the clinical setting and during controlled interventions compared with the gammacameras.

In patients with stable coronary artery disease angina pectoris is provoked by an imbalance between myocardial oxygen supply and demand. Electrocardiographic ST segment depression, a decrease in left ventricular ejection fraction, and the appearance of segmental wall motion abnormalities may all occur during episodes of myocardial ischaemia. Radionuclide angiography has been used extensively to study these changes in left ventricular function using both equilibrium blood pool and the first pass techniques. ${ }^{1-6}$ These methods have limitations when rapid sequential studies of left ventricular function are

Requests for reprints to Dr E B Raftery, Department of Cardiology, Northwick Park Hospital \& Clinical Research Centre, Watford Road, Harrow, Middlesex HA1 3UJ.

^Present Address: Cardiac Unit, Papworth Hospital, Cambridge, Cambs.

Accepted for publication 24 May 1984

required. Wagner et al $^{78}$ developed a low cost, nonimaging, computerised nuclear probe (Nuclear $O$ Stethoscope, Bios Inc), which has been used in a wide

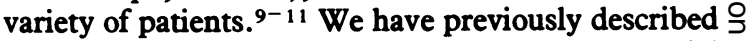
the use of this instrument for performing serial $\rightarrow$ measurements of left ventricular function. ${ }^{12-14}$

The salient features of the probe are its mobility, its $N$ low cost, and its capacity for left ventricular function measurement in both gated and beat to beat modes. O The instrument is thus highly suited to detecting and $\omega$ quantifying acute cardiovascular changes during both ${ }^{O}$ spontaneous and controlled haemodynamic events.

The aim of this study was $(a)$ to compare the $\Phi$ measurements of left ventricular ejection fraction $\stackrel{?}{+}$ obtained using the nuclear probe with those obtained $\underset{T}{T}$ using a digital gammacamera during dynamic exercise $\frac{P}{\mathbb{D}}$ in a group of normal subjects and $(b)$ to evaluate the use of the probe for measuring left ventricular ejection $\propto$ 
fraction in patients with coronary artery disease during myocardial ischaemia induced by dynamic exercise and atrial pacing. These studies were performed both before and after the administration of glyceryl trinitrate to evaluate the effects of this drug on the observed changes.

\section{Patients and methods}

\section{CONTROL GROUP}

Eleven normal male subjects underwent measurement of left ventricular function at rest and at peak exercise with the nuclear probe and a digital gammacamera. The mean age was 37 (range 26-44) years. There was no evidence of notable cardiovascular disease as assessed by history, and resting and exercise electrocardiography in these subjects.

\section{PATIENTS WITH CORONARY ARTERY DISEASE}

Twenty nine patients (two women, 27 men; age range 41-71 (mean 58) years) with a history of stable angina were selected for the study. Criteria for the selection of patients were the absence of a previous infarction and the cessation of cardiovascular medication for $\mathbf{4 8}$ hours before the study. All developed angina with at least $1.5 \mathrm{~mm}$ of horizontal ST segment depression and a reversible thallium-201 perfusion defect during assessment using methods previously described..$^{15-17}$ Twenty one of these patients underwent measurement of left ventricular function during dynamic exercise and eight underwent haemodynamic and left ventricular function studies during stress atrial pacing.

All patients gave fully informed consent and the study was approved by the hospital ethical committee.

\section{VALIDATION STUDIES}

To determine the accuracy of the nuclear probe for measuring left ventricular ejection fraction during exercise, the 11 normal volunteers underwent blood pool labelling with $740 \mathrm{MBq}$ of technetium-99m. They then had resting and exercise images recorded in the semi-supine position with the digital gammacamera (Apex, Elscint) in the left anterior oblique (best septal) view with a $10^{\circ}$ to $15^{\circ}$ caudal tilt. The window was set at $20 \%$ around a $140 \mathrm{keV}$ technetium-99m photo peak. An all purpose collimator was used to collect three million counts at rest and imaging was carried out for three minutes at peak exercise. The data were collected in the $64 \times 64$ matrix and stored in a 16 frame format. The left ventricular ejection fraction was calculated using an automatic edge detection technique. 1819

The subjects were allowed an hour's rest before left ventricular function measurement with the nuclear probe, and the study was performed in the gated mode (see below). The exercise workload was identi- cal to that used in the gammacamera study, and data were acquired for $30 \mathrm{~s}$ in the gated mode corresponding to the midpoint of the acquisition time for that study. Two independent investigators carried out the gammacamera and nuclear probe exercise studies.

\section{STUDIES OF LEFT VENTRICULAR FUNCTION}

\section{Dynamic exercise}

Semi-supine graded cycle ergometry was performed in 21 patients: 16 underwent two and five underwent three consecutive exercise tests. Exercise was carried out to a symptomatic end point on a specially constructed bicycle ergometer with an adjustable reclining seat which enabled the patients to be positioned at an angle of $25^{\circ}$ from the horizontal at a comfortable distance from the pedals. The subjects were secured to the seat with two restraining straps in order to minimise chest movement. Exercise was started at a workload of $150 \mathrm{kpm} / \mathrm{min}$ and progressively increased by $150 \mathrm{kpm} / \mathrm{min}$ increments every two minutes to peak exercise. Left ventricular function was measured during exercise and recovery from an in vivo labelled blood pool using $740 \mathrm{MBq}$ of technetium-99m and stannous pyrophosphate. Electrocardiographic monitoring was performed using the bipolar lead CM5, and ST segment depression was measured from the isoelectric line at a point $0.08 \mathrm{~s}$ after the $\mathrm{J}$ point. The nuclear probe was positioned over the left ventricle using previously described operator routines, ${ }^{7-12}$ and left ventricular function was measured after a 15 minute rest. The position of the left ventricle and background activity were marked, and the background was corrected before each measurement. At peak exercise background corrected left ventricular time activity curves were generated in the gated mode while the patient continued to exercise. The measurements were repeated at 1,5 , and 10 minutes during recovery. The patient was then allowed to rest for 30 minutes, and a single $5 \mathrm{mg}$ tablet of buccal glyceryl trinitrate ${ }^{18-22}$ was placed in the upper buccal pouch. After a further 15 minutes a resting measurement was made and the exercise procedure was repeated in 16 patients.

Background subtracted left ventricular time activity curves were generated to calculate left ventricular ejection fraction, ejection rate, and the peak filling rate. The three cursors $\left(T_{1}, T_{2}\right.$, and $\left.T_{3}\right)$ were placed as follows: $T_{2}$ at the end diastolic peak, $T_{3}$ at the end systolic nadir, and $T_{1}$ at the mid-point between $T_{2}$ and $T_{3}$ to obtain the ejection fraction (\%) and ejection rate (volume per second). Subsequently, $T_{1}$ was positioned on the end diastolic peak, and using a fixed time difference between $T_{2}$ and $T_{3}$ of $80 \mathrm{~ms}$ the rapid portion of the diastolic slope was identified to enable calculation of the peak filling rate normalised to the 
end diastolic volume (EDV per second). The background activity was corrected before each measurement.

Five patients repeated the same protocol three times: before and after a single dose of a matched buccal placebo and after a single dose of active $5 \mathrm{mg}$ buccal glyceryl trinitrate. A period of $\mathbf{3 0}$ minutes was allowed between each of these studies.

\section{Atrial pacing}

Eight patients underwent simultaneous measurement of left ventricular ejection fraction and left ventricular end diastolic pressure at rest and during an atrial stress test. A pacing wire (No 6FG) was passed to the right atrium via the right subclavian vein using the percutaneous Seldinger technique. A Millar MikroTip pressure transducer (No 7FG) was introduced into the left ventricle from the right femoral artery using the same technique. The patients then underwent a continuous pacing protocol starting at 10 beats/min above the resting heart rate and increasing by 20 beats/min every two minutes until an end point cf angina or a maximum heart rate of 210 beats/ r. in. 2021 Left ventricular end diastolic pressure was continuously recorded on a photographic recorder (Cambridge Instruments) together with the bipolar lead CM5 of the electrocardiogram. The left ventricular ejection fraction was measured at rest, during pacing, immediatley after the termination of pacing, and throughout the recovery period.

\section{CORONARY ARTERIOGRAPHY}

All 21 patients underwent diagnostic coronary arteriography in multiple views using the Judkins' technique. The cinearteriograms were reported by two independent observers and significant coronary artery disease was considered to be present when there was at least $70 \%$ luminal narrowing of at least one major coronary artery or $50 \%$ stenosis of the left main coronary artery.

\section{STATISTICAL ANALYSIS}

Statistical analysis was carried out on paired data using Student's $t$ test (two tailed). Linear regression analysis was performed in order to compare the gammacamera and nuclear probe ejection fractions. A p value of $<0.05$ was considered to be significant.

\section{Results}

\section{VALIDATION STUDY}

In the 11 normal subjects there was good correlation between the gammacamera and the nuclear probe ejection fractions both at rest and at peak exercise. The mean (SD) difference was $-0.3 \%(2.60)$ at rest and $2.3 \%(5.02)$ at peak exercise (Fig. 1). There was an increase of at least $5 \%$ in ejection fraction in all the normal subjects during both exercise periods. The mean ejection fraction at rest was $60.6(3.2)$ and increased to $72.0(6.8)$ with the gammacamera $(p<0.001)$. The probe mean ejection fraction increased from $60.4(3.0)$ to $74.2(6.5)(p<0.001)$ during exercise.

\section{EXERCISE STUDY}

The limiting symptom during exercise was angina in all 16 patients undergoing the basal study. After treatment with glyceryl trinitrate 12 out of the 16 patients became free of pain despite achieving a higher workload. The mean (SE) exercise time increased from $232(28) s$ to $339(26) s(p<0.001)$ and the mean resting heart rate increased from $75.5(3.1)$ beats/min to $88.9(2.7)$ beats/min after glyceryl trinitrate $(\mathrm{p}<0.01)$. There was a significant increase in the peak exercise heart rate from $112(3.6)$ beats $/ \mathrm{min}$ to $123.0(5.0)$ beats $/ \mathrm{min}(\mathrm{p}<0.001)$ but no significant change in heart rate gain (exercise minus resting heart rate): 36.5 (3.4) vs 34.1 (4.3) beats/min; NS. The mean maximal ST segment depression (peak exercise ST depression minus resting ST depression) was reduced from $2.19(0.2) \mathrm{mm}$ to $1.16(0.14) \mathrm{mm}$ $(p<0.001, n=16)$ (Fig. 2a and 2b).

In the 16 patients who underwent two exercise tests, the mean resting ejection fraction at rest was 52 $(3.5) \%$, ejection rate $2.31(0.26) \mathrm{vol} / \mathrm{s}$, and the peak filling rate $2.05(0.15)$ end diastolic volume per second. There was a significant fall in mean ejection fraction to $28(2.6)(\mathrm{p}<0.001)$, ejection rate to $1.27(0.13)$ $(\mathrm{p}<0.001)$, and peak filling rate to $1.71(0.16)$ $(p<0.05)$ during the initial exercise study when compared with resting values (Fig. 3). Fifteen minutes after glyceryl trinitrate administration there was a significant increase in ejection fraction to $65 \cdot 1(3 \cdot 3)$, of ejection rate to $3.57(0.42)$, and of peak filling rate to $2.87(0.21)(p<0.001)$. The second exercise period provoked a significant fall in ejection fraction to 39 (4)\% and ejection rate to $2.0(0.33)(p<0.001$ respectively) but did not alter the mean peak filling rate at 2.67 (0.33) (NS) (Table 1, Fig. 3).

In the five patients who underwent three exercise tests, there were no significant differences between the mean basal and placebo ejection fraction, ejection rate, peak filling rate, and heart rate both at rest and at peak exercise. The effect of glyceryl trinitrate in these patients was similar to that in the groups undergoing two exercise tests. The root mean square difference of ejection fraction between basal and placebo values was $4 \cdot 1 \%$ at rest and $6 \cdot 2 \%$ at the same workload as peak exercise (Table 2 and Fig. 4).

ATRIAL PACING STUDY

Because of variations in the heart rate at rest the time 

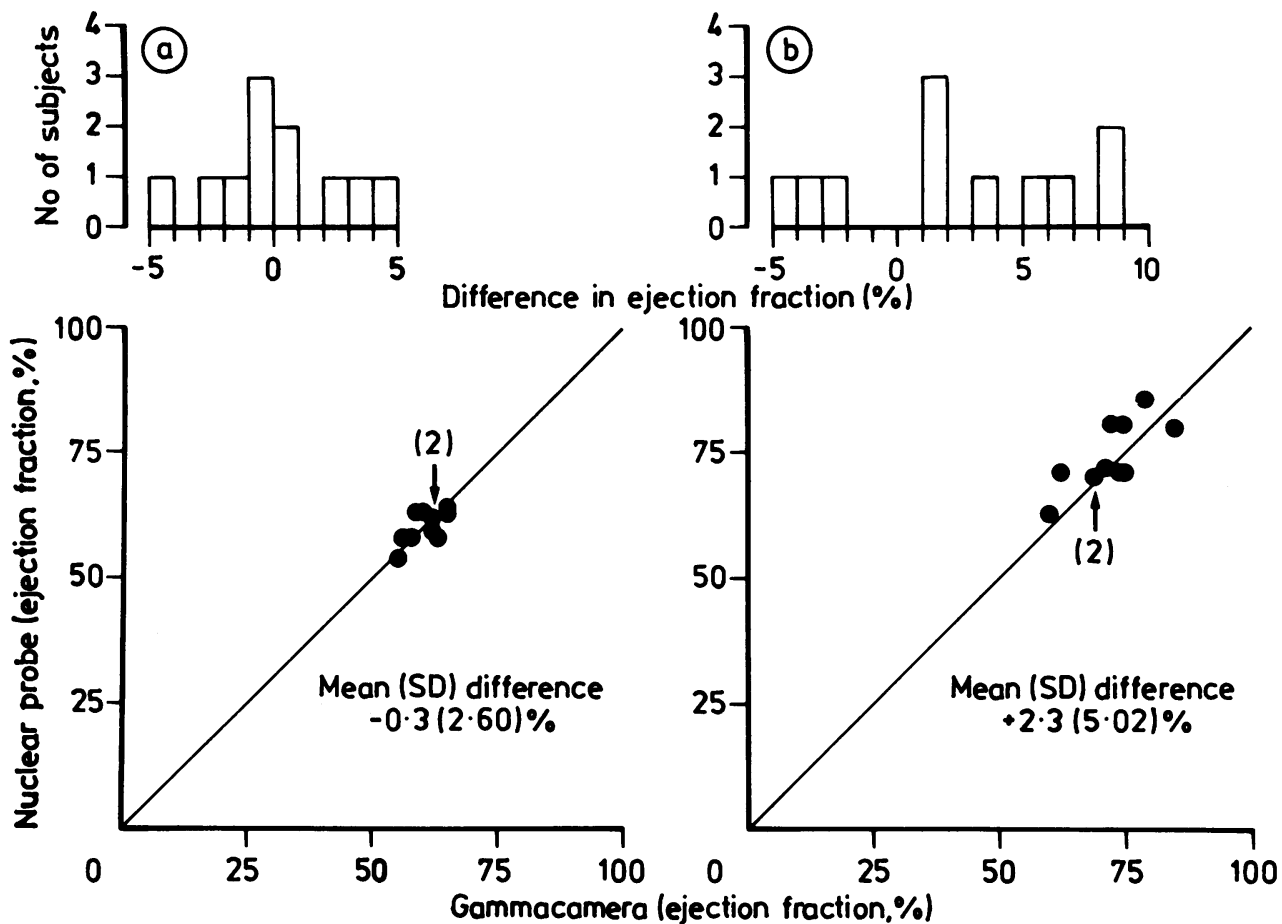

Fig. 1 Ejection fraction (a) at rest and (b) during dynamic exercise in 11 normal subjects using the non-imaging nuclear probe and a digital gammacamera.

Table 1 Results in 16 patients with coronary artery disease undergoing dynamic exercise before (basal) and after treatment with glyceryl trinitrate. Values are mean (SEM)

\begin{tabular}{|c|c|c|c|}
\hline & Basal & After & $p$ values \\
\hline $\begin{array}{l}\text { Exercise time }(\mathrm{s}) \\
\text { ST segment depression }(\mathrm{mm}) \\
\text { Heart rate (beats/min): }\end{array}$ & $\begin{array}{l}232(28) \\
2 \cdot 19(0.2)\end{array}$ & $\begin{array}{l}339(26) \\
1 \cdot 16(0.14)\end{array}$ & $\begin{array}{l}<0.001 \\
<0.001\end{array}$ \\
\hline $\begin{array}{l}\text { Resting } \\
\text { Exercise } \\
\text { Gain }\end{array}$ & $\begin{array}{l}75 \cdot 5(3 \cdot 1) \\
112.1(3.6) \\
36 \cdot 5(3.4)\end{array}$ & $\begin{array}{l}88.9(2.7) \\
123.0(5 \cdot 0) \\
34 \cdot 1(4 \cdot 3)\end{array}$ & $\begin{array}{l}<0.001 \\
<0.001 \\
\text { NS }\end{array}$ \\
\hline $\begin{array}{l}\text { Ejection fraction (\%): } \\
\text { Resting } \\
\text { Exercise }\end{array}$ & $\begin{array}{l}51.9(3.5) \\
28.1(2.6)\end{array}$ & $\begin{array}{l}65 \cdot 1(3.3) \\
39.1(4.0)\end{array}$ & $\begin{array}{l}<0.001 \\
<0.001\end{array}$ \\
\hline $\begin{array}{l}\text { Recovery } \\
1 \mathrm{~min} \\
5 \mathrm{~min} \\
10 \mathrm{~min} \\
\text { Eiection rate (vol } / \mathrm{s}) \text {. }\end{array}$ & $\begin{array}{l}39.2(4 \cdot 0) \\
47.7(4 \cdot 2) \\
51.9(3 \cdot 7)\end{array}$ & $\begin{array}{l}58.1(3.7) \\
65.3(4.4) \\
67.4(4.0)\end{array}$ & $\begin{array}{l}<0.001 \\
<0.001 \\
<0.001\end{array}$ \\
\hline $\begin{array}{l}\text { Ejection rate (vol/s): } \\
\text { Rest } \\
\text { Exercise } \\
\text { Recovery }\end{array}$ & $\begin{array}{l}2.31(0.26) \\
1.27(0.13)\end{array}$ & $\begin{array}{l}3.57(0.42) \\
2.11(0.33)\end{array}$ & $\begin{array}{l}<0.001 \\
<0.01\end{array}$ \\
\hline $\begin{array}{l}\text { Recovery } \\
1 \mathrm{~min} \\
5 \mathrm{~min} \\
10 \mathrm{~min} \\
\text { Peak filling rate (EDV/s): }\end{array}$ & $\begin{array}{l}1.84(0.21) \\
2.35(0.32) \\
2.47(0.32)\end{array}$ & $\begin{array}{l}3.77(0.45) \\
4.20(0.55) \\
4.68(0.65)\end{array}$ & $\begin{array}{l}<0.001 \\
<0.001 \\
<0.01\end{array}$ \\
\hline $\begin{array}{l}\text { Rest } \\
\text { Exercise } \\
\text { Recovery }\end{array}$ & $\begin{array}{l}2.05(0.15) \\
1.71(0.16)\end{array}$ & $\begin{array}{l}2.87(0.21) \\
2.67(0.21)\end{array}$ & $\begin{array}{l}<0.001 \\
<0.001\end{array}$ \\
\hline $\begin{array}{l}1 \mathrm{~min} \\
5 \mathrm{~min} \\
10 \mathrm{~min}\end{array}$ & $\begin{array}{l}1.98(0.16) \\
2.17(0.17) \\
2.14(0.13)\end{array}$ & $\begin{array}{l}2.71(0.24) \\
2.98(0.28) \\
3.22(0.27)\end{array}$ & $\begin{array}{l}<0.01 \\
<0.01 \\
<0.002\end{array}$ \\
\hline
\end{tabular}



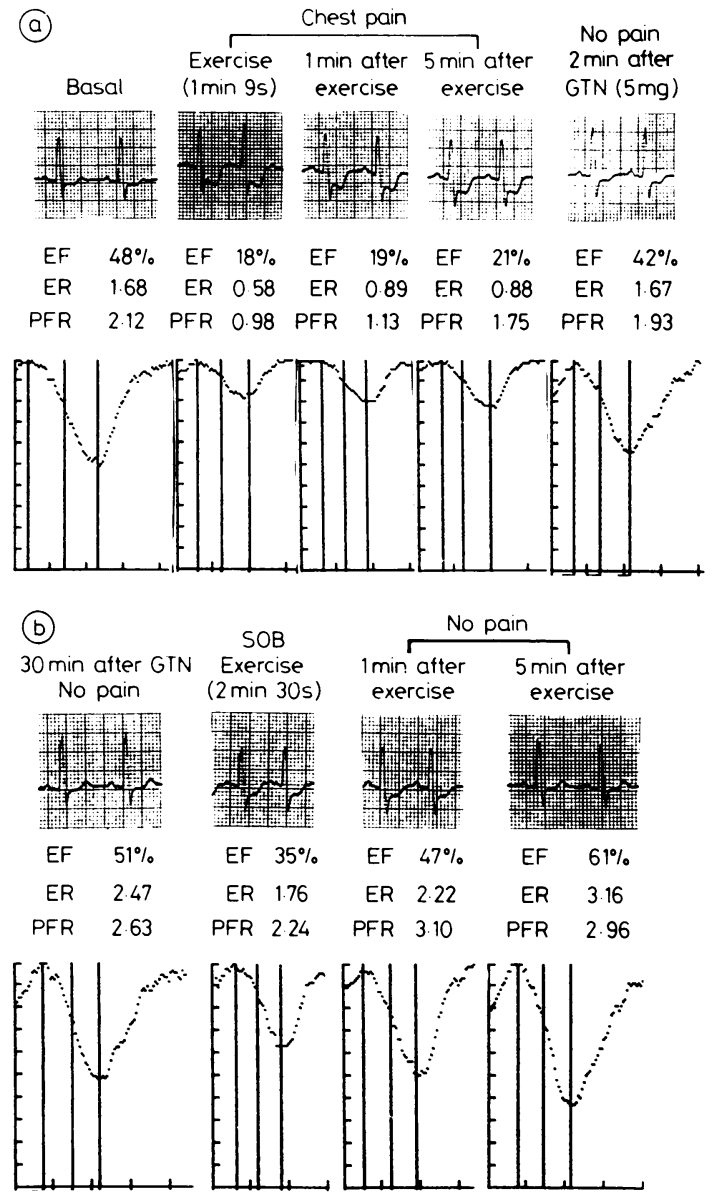

Fig. 2 Electrocardiogram (lead CM5) and left ventricular time activity curves generated by the nuclear stethoscope in a patient with three vessel coronary artery disease: (a) shows the exercise-induced changes before treatment with buccal glyceryl trinitrate $(G T N)$ and $(b)$ shows the results from a second exercise test performed by the same patient 30 min after treatment with 5 mg of buccal GTN. EF, ejection fraction; $E R$, ejection rate (vol/s); PFR, peak filling rate (end diastolic volume/s).

to angina was defined as the total pacing time during the first pacing study. The mean pacing time increased from $69(6) \mathrm{s}$ to $180(31) \mathrm{s}(\mathrm{p}<0.02)$ after glyceryl trinitrate. All patients developed angina during the basal study but only two developed angina after glyceryl trinitrate. Because of triggering artefacts produced by the pacing spike, the gated time activity curves could not be generated during peak pacing but were obtained immediately after pacing. Acquisition times were reduced owing to higher count rates from the left ventricle during peak stress, and $15 \mathrm{~s}$ acquisitions were obtained at this point. The mean ejection fraction was $46(5 \cdot 1) \%$ at rest and fell to $34(3.2) \%$ during the initial study $(p<0.05)$. After glyceryl trinitrate administration the resting ejection fraction increased to $52 \%(5.3)$ and fell to $38 \%(6.4)$ during pacing (NS); however, this change occurred at a higher heart rate.

The mean left ventricular end diastolic pressure increased from $8.4(1.2) \mathrm{mm} \mathrm{Hg}$ at rest to $15.9(2.3)$ $\mathrm{mm} \mathrm{Hg}$ at peak pacing $(\mathrm{p}<0.01)$. The mean value 15 minutes after glyceryl trinitrate was $6.1(1.5) \mathrm{mm} \mathrm{Hg}$ (NS, compared with basal values). During the repeat atrial pacing study a significant increase in pacing time occurred without an increase in the left ventricular end diastolic value $(6.4(1.9) \mathrm{mm} \mathrm{Hg}$; NS).

\section{CORONARY ARTERIOGRAPHY}

Table 3 shows the results of coronary arteriography.

\section{Discussion}

The non-imaging nuclear probe is a unique instrument, which is readily portable and may be used in most clinical settings. The count sensitivity of the detector allows rapid acquisition of high resolution left ventricular volume curves from which measurements of both systolic and diastolic left ventricular function can be made.

Previous authors have compared left ventricular ejection fraction measurements obtained by gammacameras with those obtained by the nuclear probe at rest and have established a range of correlation coefficients from 0.81 to $0.92 .^{8-11}$ Our own results, from a previous study, are in agreement with these findings: $r=0.94, p<0.001$ for 54 patients, with a mean (SD) difference of $1.37 \%(6.5) .{ }^{22}$

The normal volunteer data which we obtained suggest that it is also possible accurately to measure left ventricular ejection fraction during exercise with the nuclear probe. The placebo controlled study as well as the normal volunteer study confirmed the reproducibility of exercise ejection fraction measurements with the nuclear probe using our technique, albeit in a small number of subjects.

In order to obtain accurate exercise data the design of an exercise protocol should aim to minimise thoracic movement and reduce the acquisition time during peak exercise. ${ }^{23}$ Furthermore, previous studies have shown that an increase in cardiopulmonary blood volume ${ }^{2324}$ and transient pulmonary oedema ${ }^{25}$ may occur during exercise induced myocardial ischaemia in patients with coronary heart disease. This may result in increased background activity. Since glyceryl trinitrate primarily reduces left ventricular preload the increased cardiopulmonary blood volume may be reset rapidly, causing a downward shift in background activity after glyceryl trinitrate. It is therefore important to correct for background activ- 
Table 2 Indices of left ventricular function in five patients with coronary artery disease before (basal) and after treatment with placebo or glyceryl trinitrate at rest, during peak exercise, and at recovery. Values are mean (SEM)

\begin{tabular}{|c|c|c|c|c|c|}
\hline & Basal & $p$ values & After placebo & p values & $\begin{array}{l}\text { After glyceryl } \\
\text { trinitrate }\end{array}$ \\
\hline $\begin{array}{l}\text { Exercise time }(\mathrm{min}) \\
\text { Eiection fraction }(\%) \text {. }\end{array}$ & $4.47(0.4)$ & NS & $4.75(0.5)$ & $<0.05$ & $6 \cdot 74$ \\
\hline $\begin{array}{l}\text { Rest } \\
\text { Peak exercise } \\
\text { Recovery }\end{array}$ & $\begin{array}{l}59.2(4.2) \\
32.6(3.2)\end{array}$ & $\begin{array}{l}\text { NS } \\
\text { NS }\end{array}$ & $\begin{array}{l}57.2(4.2) \\
36.6(2 \cdot 3)\end{array}$ & $\begin{array}{l}<0.02 \\
\text { NS }\end{array}$ & $\begin{array}{l}69.8(4.4) \\
39.2(6.4)\end{array}$ \\
\hline $\begin{array}{l}1 \mathrm{~min} \\
5 \mathrm{~min} \\
10 \mathrm{~min} \\
\text { Eiection rate (vol/s): }\end{array}$ & $\begin{array}{l}49.8(5.6) \\
54.8(3.2) \\
56.8(4.3)\end{array}$ & $\begin{array}{l}\text { NS } \\
\text { NS } \\
\text { NS }\end{array}$ & $\begin{array}{l}51.2(5.3) \\
59.0(2.7) \\
55.8(?)\end{array}$ & $\begin{array}{l}\text { NS } \\
\text { NS } \\
\text { NS }\end{array}$ & $\begin{array}{l}59.0(3.9) \\
67.2(5 \cdot 1) \\
65.2(4.4)\end{array}$ \\
\hline $\begin{array}{l}\text { Rest } \\
\text { Peak exercise } \\
\text { Recovery }\end{array}$ & $\begin{array}{l}2.84(0.5) \\
1.59(0.2)\end{array}$ & $\begin{array}{l}\text { NS } \\
\text { NS }\end{array}$ & $\begin{array}{l}3.03(0.4) \\
1.70(0.2)\end{array}$ & $\begin{array}{l}\text { NS } \\
\text { NS }\end{array}$ & $\begin{array}{l}4.81(0.8) \\
2.29(0.6)\end{array}$ \\
\hline $\begin{array}{l}1 \mathrm{~min} \\
5 \mathrm{~min} \\
10 \mathrm{~min} \\
\text { Peak filling rate }(\mathrm{EDV} / \mathrm{s}) \text { : }\end{array}$ & $\begin{array}{l}2.33(0.3) \\
2.81(0.2) \\
2.75(2.55)\end{array}$ & $\begin{array}{l}\text { NS } \\
\text { NS } \\
\text { NS }\end{array}$ & $\begin{array}{l}2.64(0.3) \\
2.85(0.3) \\
2.55(0.3)\end{array}$ & $\begin{array}{l}<0.05 \\
\text { NS } \\
\text { NS }\end{array}$ & $\begin{array}{l}3.86(0.5) \\
4.67(0.9) \\
4.26(0.9)\end{array}$ \\
\hline $\begin{array}{l}\text { Rest } \\
\text { Peak exercise } \\
\text { Recovery }\end{array}$ & $\begin{array}{l}2.41(0.2) \\
2.17(0.3)\end{array}$ & $\begin{array}{l}\text { NS } \\
\text { NS }\end{array}$ & $\begin{array}{l}2.59(0.2) \\
2.21(0.1)\end{array}$ & $\begin{array}{l}\text { NS } \\
\text { NS }\end{array}$ & $\begin{array}{l}3.08(0.3) \\
2.94(0.4)\end{array}$ \\
\hline $\begin{array}{l}1 \mathrm{~min} \\
5 \mathrm{~min} \\
10 \mathrm{~min}\end{array}$ & $\begin{array}{l}2.45(0.1) \\
2.55(0.1) \\
2.46(0.2)\end{array}$ & $\begin{array}{l}\text { NS } \\
\text { NS } \\
\text { NS }\end{array}$ & $\begin{array}{l}2.55(0.5) \\
2.35(0.1) \\
2.44(0.2)\end{array}$ & $\begin{array}{l}\text { NS } \\
\text { NS } \\
\text { NS }\end{array}$ & $\begin{array}{r}2.56(0.3) \\
3.18(0.3) \\
3.12(0.3)\end{array}$ \\
\hline \multicolumn{6}{|c|}{ At same workload as placebo } \\
\hline $\begin{array}{l}\text { Ejection fraction (\%): } \\
\text { Rest } \\
\text { Exercise } \\
\text { Ejection rate (vol/s): }\end{array}$ & & & $\begin{array}{l}57.2(4 \cdot 2) \\
36.6(2 \cdot 3)\end{array}$ & $\begin{array}{l}<0.02 \\
<0.05\end{array}$ & $\begin{array}{l}69.8(4.4) \\
53.0(5.0)\end{array}$ \\
\hline $\begin{array}{l}\text { Ejection rate (vol/s): } \\
\text { Rest } \\
\text { Exercise }\end{array}$ & & & $\begin{array}{l}3.03(0.4) \\
1.70(0.2)\end{array}$ & $\begin{array}{l}\text { NS } \\
<0.01\end{array}$ & $\begin{array}{l}4.81(0.8) \\
3.07(0.4)\end{array}$ \\
\hline $\begin{array}{l}\text { Peak filling rate (EDV/s): } \\
\text { Rest } \\
\text { Exercise } \\
\text { Heart rate during exercise }\end{array}$ & & & $\begin{array}{l}2.59(0.2) \\
2.21(0.1) \\
115.6(6.5)\end{array}$ & $\begin{array}{l}\text { NS } \\
<0.01 \\
\text { NS }\end{array}$ & $\begin{array}{l}3.08(0.3) \\
3.26(0.2) \\
118.8(7.9)\end{array}$ \\
\hline
\end{tabular}

ity during such interventions in patients with coronary disease, particularly when using the non-imaging nuclear probe. Another potential problem is that the gating signal is an integrated electrocardiographic signal; this leads to gating inaccuracies from the pacing spike, and we were able to measure left ventricular performance only in the immediate period after pacing. ${ }^{26}$

In our patients with coronary artery disease a significant fall in ejection fraction occurred during dynamic exercise. Nevertheless, this fall was greater than has been reported by others. ${ }^{24-68}$ This difference may be explained by the fact that our patients had relatively severe coronary artery disease with exercise induced angina associated with evidence of severe myocardial ischaemia and were untreated at the time of the studies. Exercise was continued until a symptom limited end point, when data were acquired. The severity of disease in our patients was further reflected by the significant reduction in mean ejection fraction which was still present after one minute of recovery. Equilibrium blood pool angiography using a gammacamera requires 2-4 minutes to acquire data, and the ejection fraction values therefore represent the mean ejection fraction over this period of acquisition. On the other hand the nuclear probe required only $15-30 \mathrm{~s}$ to obtain a time activity curve, and the data therefore represent left ventricular performance at peak exercise.

Atrial pacing has been established as a useful technique for studying the haemodynamic and metabolic responses during myocardial ischaemia. ${ }^{27}$ Atrial pacing was performed in order to determine simultaneous changes in left ventricular end diastolic pressure and ejection fraction. There was a significant increase in left ventricular end diastolic pressure and a fall in ejection fraction during pacing induced angina. Despite a higher pacing rate intervention with glyceryl trinitrate prevented angina in six out of eight patients and also abolished the rise in left ventricular end diastolic pressure while attenuating the fall in ejection fraction.

Glyceryl trinitrate increased both the ejection fraction and the ejection rate at rest. Although exercise time was prolonged after administration, the magnitude of fall of both ejection fraction and ejection rate was similar. Although the mechanisms of action of glyceryl trinitrate are complex, the principal haemodynamic effects are a reduction in right atrial pressure and pulmonary capillary wedge pressure and a decrease in systemic arterial pressure. ${ }^{28} 29$ Brown et al have shown that nitrates dilate both normal and 

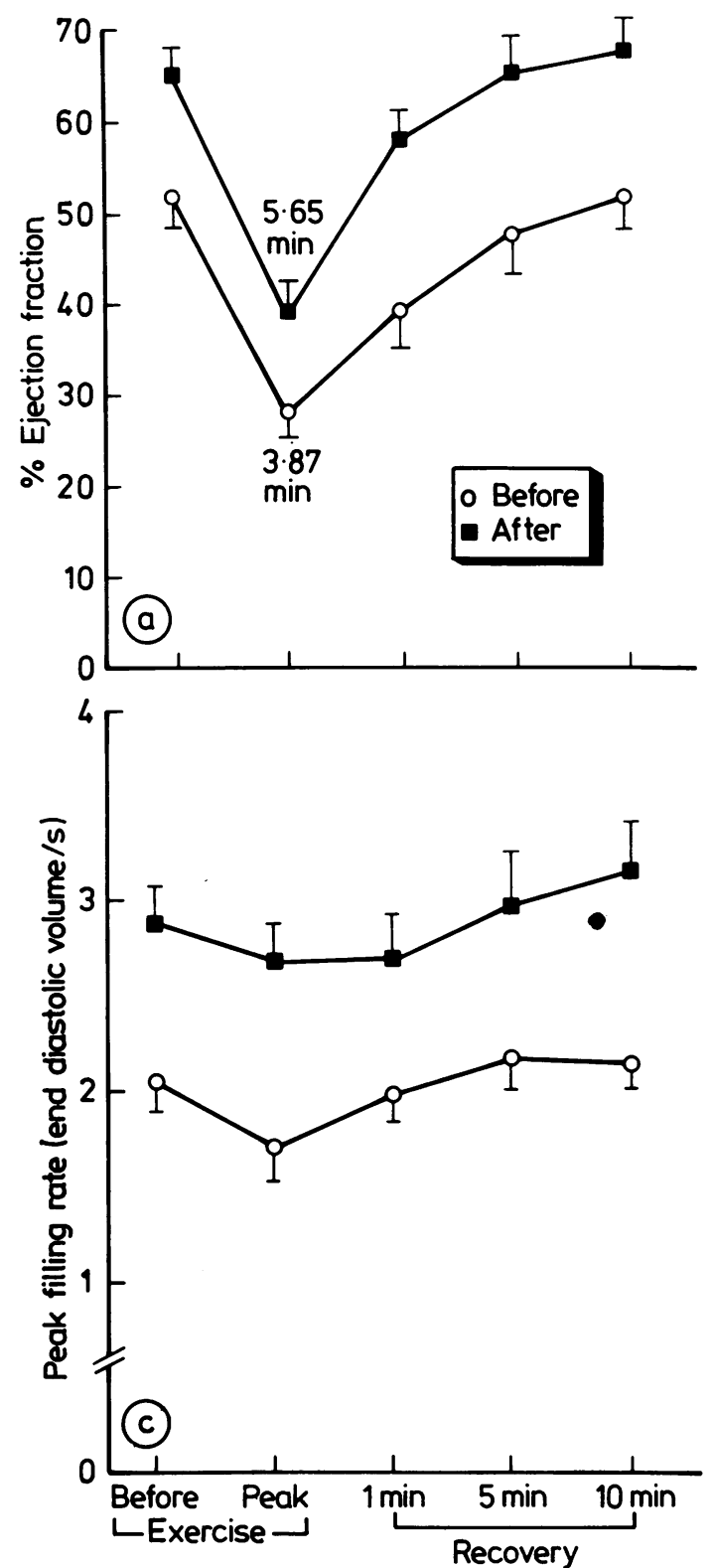

Fig. 3 Change in (a) mean ejection fraction, $(b)$ mean ejection rate, and (c) peak filling rate during exercise and recovery for 16 patients with coronary artery disease before and after treatment with $5 \mathrm{mg}$ buccal glyceryl trinitrate. Min, mean exercise time. Bars represent SEM.

diseased coronary arteries. ${ }^{30}$ Relief of exercise induced myocardial ischamia with nitrates is therefore likely to be multifactorial. $29-31$ The buccal formulation of glyceryl trinitrate ${ }^{32-36}$ was used in this experiment in order to provide stable blood concentrations

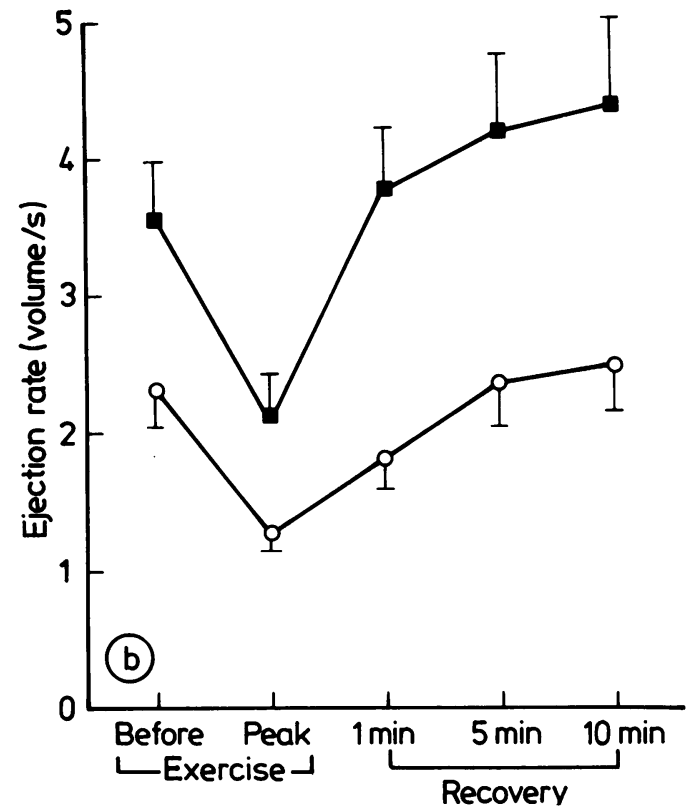

Table 3 Results of coronary arteriography in 16 patients undergoing two exercise tests and in five undergoing three and in eight during atrial pacing *

\begin{tabular}{|c|c|c|c|c|}
\hline & $L A D$ & $L C X$ & $R C A$ & $L M S>50 \%$ \\
\hline \multicolumn{5}{|c|}{ Two exercise tests } \\
\hline 1 & + & & + & + \\
\hline 2 & + & + & + & + \\
\hline 3 & + & + & - & + \\
\hline 4 & + & + & + & - \\
\hline 5 & + & + & $\begin{array}{l}+ \\
+\end{array}$ & $\overline{-}$ \\
\hline $\begin{array}{l}6 \\
7\end{array}$ & $\begin{array}{l}+ \\
+\end{array}$ & $\begin{array}{l}+ \\
+\end{array}$ & $\begin{array}{l}+ \\
+\end{array}$ & - \\
\hline 8 & + & + & + & - \\
\hline 9 & + & + & + & - \\
\hline 10 & + & + & + & - \\
\hline 11 & + & + & + & - \\
\hline 12 & + & - & + & - \\
\hline 13 & + & + & - & - \\
\hline 14 & - & + & - & - \\
\hline 15 & - & + & - & - \\
\hline 16 & - & + & - & - \\
\hline \multicolumn{5}{|c|}{ Three exercise tests } \\
\hline 1 & + & + & + & - \\
\hline 2 & + & + & + & - \\
\hline 3 & - & + & + & - \\
\hline 4 & - & - & + & - \\
\hline 5 & - & + & - & - \\
\hline \multicolumn{5}{|c|}{ Atrial pacing } \\
\hline 1 & + & + & + & + \\
\hline 2 & + & + & + & - \\
\hline 3 & + & + & + & - \\
\hline $\begin{array}{l}4 \\
5\end{array}$ & $\begin{array}{l}+ \\
+\end{array}$ & $\begin{array}{l}+ \\
+\end{array}$ & $\begin{array}{l}+ \\
+\end{array}$ & - \\
\hline 6 & + & - & + & - \\
\hline 7 & + & - & + & - \\
\hline 8 & + & + & - & - \\
\hline
\end{tabular}

$\star$ Significant luminal narrowing denotes the presence of $>70 \%$ narrowing in any one major coronary artery.

LAD, left anterior descending; LCX, left circumflex; RCA, right coronary artery; LMS $>50 \%$, left main stem with greater than $\mathbb{D}$ $50 \%$ lesion. 


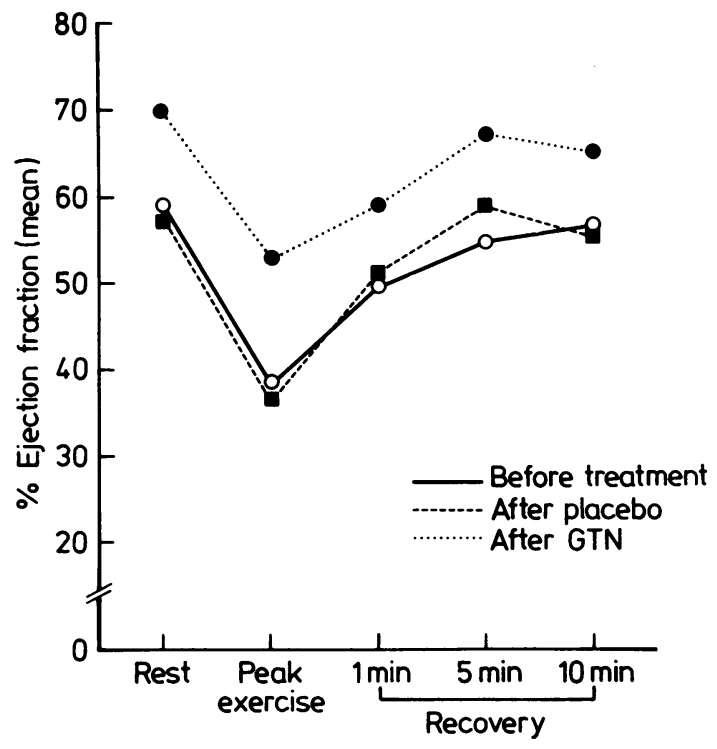

Fig. 4 Reproducibility of ejection fraction response to exercise in five patients with stable angina before and after treatment with a placebo or $5 \mathrm{mg}$ buccal glyceryl trinitrate (GTN). The root mean square difference of ejection fraction at peak exercise between basal and placebo studies was $6 \cdot 2 \%$.

during the extended study period. We have also found a significant effect of glyceryl trinitrate on the diastolic peak filling rate at rest and during exercise and this improvement in compliance may be an important factor in improving cardiac function. ${ }^{37-40}$

An improvement in patient monitoring may be achieved by applying the probe concept to miniature semi-conductor detectors such as cadmium telluride detectors ${ }^{41}$ or high efficiency miniature solid state mercuric iodide detectors ${ }^{22}$ for continuous left ventricular function monitoring with greater ease during such interventions.

The high temporal resolution of the nuclear probe lends itself to monitoring rapid changes in left ventricular function in the beat to beat ${ }^{1326}$ and the gated modes. The probe technology may be adapted for studying cardiovascular responses to drug treatment, and to physiological interventions and may be applied to the study of both induced and spontaneous myocardial ischaemia. ${ }^{12-1442}$

We thank Mr David Hinge, Mrs Rita Cox, and Dr G D Zannelli for valuable technical assistance.

\section{References}

1 Strauss HW, Zaret BL, Hurley PJ, Natarajan TK, Pitt B. A scintiphotographic method for measuring left ventricular ejection fraction in man without cardiac catheterization. Am f Cardiol 1971; 28: 575-80.
2 Borer JS, Kent KM, Bacharach SL, et al. Sensitivity, specificity and predictive accuracy of radionuclide cineangiography during exercise in patients with coronary artery disease: comparison with exercise electrocardiography. Circulation 1979; 60: 572-80.

3 Upton MT, Rerych SK, Newman GE, Bounous EP Jr, Jones RH. The reproducibility of radionuclide angiographic measurements of left ventricular function in normal subjects at rest and during exercise. Circulation 1980; 62: 126-32.

4 Marshall RC, Berger HJ, Reduto LA, Gottschalk A, Zaret BL. Variability in sequential measures of left ventricular performance assessed with radionuclide angiography. Am $\mathcal{F}$ Cardiol 1978; 41: 531-6.

-5 Jengo MA, Mena I, Blaufuss A, Criley JM. Evaluation of left ventricular function (ejection fraction and segmental wall motion) by single pass radioisotope angiography. Circulation 1978; 57: 326-32.

6 Slutsky R, Karliner J, Ricci D, et al. Response of left ventricular volume to exercise in man assessed by radionuclide equilibrium angiography. Circulation 1979; 60: $565-71$.

7 Wagner HN Jr, Wake R, Nickoloff E, Natarajan TK. The nuclear stethoscope: a simple device for generation of left ventricular volume curves. Am $\mathcal{F}$ Cardiol 1976; 38: 747-50.

8 Wagner HN Jr, Rigo P, Baxter RH, Alderson PO, Douglass PO, Housholder DF. Monitoring ventricular function at rest and during exercise with a nonimaging nuclear detector. Am $\mathcal{F}$ Cardiol 1979; 43: 975-9.

9 Berger HJ, Davies RA, Batsford WP, Hoffer PB, Gottschalk A, Zaret BL. Beat-to-beat left ventricular performance assessed from the equilibrium cardiac blood pool using a computerized nuclear probe. Circulation 1981; 63: $133-42$.

10 Strashun A, Horowitz SF, Goldsmith SJ, et al. Noninvasive detection of left ventricular dysfunction with a portable electrocardiographic gated scintillation probe device. Am 7 Cardiol 1981; 47: 610-7.

11 Hilund-Carlsen PF, Marving J, Jensen G. Accuracy of left ventricular ejection fraction determined by the nuclear stethoscope. Int $\mathcal{F}$ Cardiol 1982; 2: 237-46.

12 Bowles MJ, Lahiri A, Jones R, Cooper WD, Raftery EB. Diastolic dysfunction in chronic stable angina. Intraexercise comparison of abnormal impedance waveform with changes in ejection fraction and diastolic filling $[\mathrm{Ab}-$ stract]. Clin Sci 1983; 64: 31P.

13 O'Hara MJ, Lahiri A, Raftery EB. Exercise-induced left ventricular dysfunction precedes ST-segment depression in patients with angina: a non-imaging nuclear probe study [Abstract]. Nuclear Medicine Communications 1984; 5: 265 .

14 Jones R, Lahiri A, Bowles MJ, Raftery EB. The relative value of cold stress, isometric handgrip and maximal dynamic exercise for eliciting left ventricular dysfunction following myocardial infarction [Abstract]. Clin Sci 1983; 64: 46-47P.

15 Lahiri A, Balasubramanian V, Millar-Craig MW, Crawley J, Raftery EB. Exercise-induced ST-segment in variant angina. Am $\mathcal{F}$ Cardiol 1980; 45: 887-94.

16 Lahiri A, Carboni GP, Crawley JW, Raftery EB. Reversible ischaemia of right ventricle detected by exercise 
thallium-201 scintigraphy. $B r$ Heart $\mathcal{F}$ 1982; 48: 260-4.

17 Pohost GM, Zir LM, Moore RH, McKusick KA, Guiney TE, Beller GA. Differentiation of transiently ischemic from infarcted myocardium by serial imaging after a single dose of thallium-201. Circulation 1977; 55: 294-302.

18 Bourguignon MH, Douglass KH, Links JM, Wagner HN Jr. Fully automated data acquisition, processing and display in equilibrium radioventriculography. Eur $\mathcal{F} \mathrm{NuCl}$ Med 1981; 6: 343-7.

19 Slutsky R, Pfisterer M, Verba J, Battler A, Ashburn W. Influence of different background and left ventricular assignments on the ejection fraction in equilibrium radionuclide angiography. Radiology 1980; 135: 725-30.

20 Linhart JW, Hildner FJ, Barold SS, Lister JW, Samet P. Left heart hemodynamics during angina pectoris induced by atrial pacing. Circulation 1969; 40: 483-92.

21 Thadani U, Lewis JR, Mathew TM, West RO, Parker JO. Reproducibility of clinical and hemodynamic parameters during pacing stress testing in patients with angina pectoris. Circulation 1979; 60: 1036-44.

22 Lahiri A, Crawley JCW, Jones RI, Bowles MJ, Raftery EB. A non-invasive technique for continuous monitoring of left ventricular function using a new solid state mercuric iodide radiation detector. Clin Sci 1984; 66: 551-6.

23 Okada RD, Boucher CA, Strauss HW, Pohost GM. Exercise radionuclide imaging approaches to coronary artery disease. Am f Cardiol 1980; 46: 1188-204.

24 Nichols AB, Strauss HW, Moore RH, et al. Acute changes in cardiopulmonary blood volume during upright exercise stress testing in patients with coronary heart disease. Circulation 1979; 60: 520-30.

25 Lahiri A, O'Hara M, Bowles MJ, Crawley JCW, Raftery EB. Influence of left ventricular function and severity of coronary artery disease on exercise-induced pulmonary thallium-201 uptake. Int $\mathcal{F}$ Cardiol 1984; 5: 475-90.

26 Perrins EJ, Hudson WM, Lahiri A, Crawley JCW, Sutton R, Raftery EB. Randomised controlled study of DDD and incremental VVI rate responsive pacing [Abstract]. Am $f$ Cardiol 1984; 3: 507.

27 Parker JO, Chiong MA, West RO, Case RB. Sequential alterations in myocardial lactate metabolism, ST segments, and left ventricular function during angina induced by atrial pacing. Circulation 1969; 40: 113-31.

28 Abrahams J. Nitroglycerin and long acting nitrates. $N$ Engl f Med 1980; 302: 1234-7.

29 Chatteriee K, Parmley WW. Vasodilator therapy for acute myocardial infarction and chronic congestive heart failure. $\mathcal{F}$ Am Coll Cardiol 1983; 1: 133-53.

30 Brown BG, Bolson E, Petersen RB, Pierce CD, Dodge HT. The mechanisms of nitroglycerin action: stenosis vasodilation as a major component of the drug response.
Circulation 1981; 64: 1089-97.

31 Borer JS, Redwood DR, Itscoitz SB, Goldstein RE, Epstein SE. Nitroglycerin-induced improvement in exercise tolerance and hemodynamics in patients with chronic rheumatic heart valve disease. Am $\mathcal{F}$ Cardiol 1978; 41: 302-7.

32 Erb RJ. Bioavailability of controlled release buccal and oral nitroglycerin by digital plethysmography. In: Bussman WD, Dries RR, Wagner W, eds. Advances in pharmacotherapy. Vol. 1. Basel: Karger, 1982: 35-43.

33 Abrams J. New nitrate delivery systems. 1. Buccal nitroglycerin. Am Heart $\mathcal{F}$ 1983; 105: 848-54.

34 Reichek N, Priest C, Kienzle M, et al. Angina prophylaxis with buccal synchron nitroglycerin: a rapid onset long-acting nitrate. In: Bussman WD, Dries RR, Wagner W, eds. Advances in pharmacotherapy. Vol. 1. Basel: Karger, 1982: 143-54.

35 Sonecha TN, Lahiri A, Crawley JCW, Cooper D, Raftery EB. Correlation between left ventricular segmental wall motion abnormalities and global ejection fraction [Abstract]. Clin Sci 1983; 64: 47P.

36 Lahiri A, Crawley JCW, Sonecha TN, Raftery EB. Acute and chronic effects of sustained action buccal nitroglycerin in severe congestive heart failure. Int $\mathcal{F}$ Cardiol 1984; 5: 39-48.

37 Bonow RO, Bacharach SL, Green MV, et al. Impaired left ventricular diastolic filling in patients with coronary artery disease: assessment with radionuclide angiography. Circulation 1981; 64: 315-23.

38 Reduto LA, Wickemeyer WJ, Young JB, et al. Left ventricular diastolic performance at rest and during exercise in patients with coronary artery disease. Assessment with first-pass radionuclide angiography. Circulation 1981; 63: 1228-37.

39 Mancini GBJ, Slutsky RA, Norris SL, Bhargava V, Ashburn WL, Higgins CB. Radionuclide analysis of peak filling rate, filling fraction and time to peak filling rate. Response to supine bicycle exercise in normal subjects and patients with coronary disease. Am $\mathcal{F}$ Cardiol 1983; 51: 43-51.

40 Bonow RO, Kent KM, Rosing DR, et al. Improved left ventricular diastolic filling in patients with coronary artery disease after percutaneous transluminal coronary angioplasty. Circulation 1983; 66: 1159-67.

41 Hoffer PB, Berger HJ, Steidley J, et al. A miniature cadmium telluride detector module for continuous monitoring of left ventricular function. Radiology 1981; 138: 477-81.

42 Chierchia S, Davies G, Berkenboom G, Crea F, Crean P, Maseri A. Alpha adrenergic receptors and coronary spasm: an elusive link. Circulation 1984; 69: 8-14. 